\title{
Manual vacuum aspiration under local anaesthetic for early miscarriage: 2 years experience in a university teaching hospital in UK
}

\author{
Vinod Kumar • Jonathan Chester • Janesh Gupta • \\ Manjeet Shehmar
}

Received: 1 April 2013 /Accepted: 24 June 2013 /Published online: 5 July 2013

(C) Springer-Verlag Berlin Heidelberg 2013

\begin{abstract}
Manual vacuum aspiration under local anaesthesia (MVA-LA) in an outpatient setting is an alternative to the standard surgical aspiration under general anaesthesia for miscarriage. We evaluate the feasibility, safety and clinical outcomes of MVA-LA in the management of miscarriage at less than 12 weeks of gestation in an outpatient setting. This prospective cohort study was conducted at the Birmingham Women's Hospital. One hundred and thirty-one women with ultrasound scan confirmed incomplete or missed miscarriage underwent MVA-LA between November 2010 and January 2013. A computer database was used to record relevant information. The mean gestation age was 8.3 weeks $( \pm 1.8)$. Successful evacuation was achieved in $100 \%$ of cases. One hundred and fourteen $(87 \%)$ patients underwent the procedure with direct intracervical LA block and the remaining cases did not have LA. There were no reported complications in $96 \%$ of procedures. Cervical injury and vasovagal symptoms noted in $3.8 \%$ of cases. In all cases, vaginal bleeding was minimal or mild. The post-operative pain was controlled successfully with a combination of paracetamol and diclofenac in $82 \%$ of patients. The MVA method was associated with high levels (93\%) of patient satisfaction and acceptability. MVA-LA in an outpatient setting is a safe and
\end{abstract}

V Kumar and J Chester have contributed equally to this research.

V. Kumar $(\bowtie)$

University Hospitals Birmingham NHS Foundation Trust,

Birmingham, UK

e-mail: vinodkumar1@nhs.net

J. Chester

Good Hope Hospital, Birmingham, UK

J. Gupta $\cdot$ M. Shehmar

Birmingham Women's NHS Foundation Trust,

Birmingham, UK acceptable therapeutic option for women diagnosed with early missed or incomplete miscarriage.

Keywords Vacuum curettage/methods · Early pregnancy loss · Manual vacuum aspiration - Early miscarriage management $\cdot$ Surgical evacuation

\section{Background}

In 2009 , over 45,000 of 900,000 pregnancies ended with miscarriage in England and Wales [1, 2]. In the UK, current guidelines provide several options for the management of miscarriage; expectantly by awaiting spontaneous expulsion of the remaining products, medically with misoprostol or surgically by evacuation of the uterus [3, 4]. Expectant and medical management have good efficacy rates of 70-80\% [5] although these methods are proved to be less acceptable to women $[6,7] ; 88 \%$ of women are managed through surgical methods, mainly electric vacuum aspiration (EVA) under general anaesthesia (GA) $[8,9]$. However, an alternative method now exists, in the form of manual vacuum aspiration (MVA).

Unlike EVA, MVA is a light-weight, quiet, inexpensive syringe which can be used under local anaesthetic in a clinic or ward environment and does not require electricity, which makes it especially useful in emergencies. Many studies have shown MVA to be comparable to EVA in efficacy and rates of complications, such as uterine bleeding and perforation [10-14]. Data from a cost analysis study has shown that MVA performed in the ambulatory setting is significantly less expensive than EVA performed under GA [15]. Despite the proven benefits, MVA under local anaesthesia (LA) is still underused in the United Kingdom [14, 16, 17].

Given the current economic climate and the benefits shown in previous studies, a service was set up in November 
2010 at Birmingham Women's Hospital. MVA under LA was offered in the outpatient setting to women following an incomplete or early miscarriage within the first 12 weeks of gestation. The aim of this study was to assess the feasibility, safety and clinical outcomes of MVA under LA in the outpatient setting.

\section{Methods}

This prospective cohort study was carried out between November 2010 and January 2013. All women, with ultrasound scan (USS) confirmed incomplete or early missed miscarriage at less than 12 weeks of gestation, were offered the MVA procedure under LA as an option for the management of miscarriage. Exclusion criteria included suspected septic miscarriage, known uterine anomalies, molar pregnancy, multiple pregnancy and previous cervical knife cone treatment.

Written consent was obtained by the operating surgeon on the gynaecological ward prior to the procedure. All patients were given the option of further intra-operative analgesia or Entonox $^{\circledR}(50 \%$ nitrous oxide and $50 \%$ oxygen; BOC Healthcare, Manchester, UK) should they require it.

As the procedure was performed under local anaesthetic, there was no need to fast beforehand. Therefore, all elective patients were encouraged to eat and drink before the procedure to reduce the incidence of hypoglycaemia and vasovagal episodes [18]. As per protocol, all women were administered $800 \mu \mathrm{g}$ of vaginal misoprostol (Pharmacia Ltd. Milton Keynes, UK) for cervical priming at least $2 \mathrm{~h}$ before the procedure. All patients had a full blood count and group and save measured before the procedure except in emergency cases.

The procedure was mostly performed electively in the outpatient setting by two hospital consultants in the early pregnancy assessment unit (EPAU). However, in emergency situations of heavy haemorrhage with cardiovascular compromise, the procedure was carried out in the gynaecology ward treatment room, accident and emergency (A\&E) or in an operating theatre. Pre-procedure vaginal misoprostol was not administered in emergency situations.

During the MVA, every effort was made to keep the procedure room a relaxed and comfortable environment. One dedicated registered nurse and one health care assistant (HCA) were present to support the clinician performing the procedure. The patient was positioned on a couch in a lithotomy position and a HCA stood beside her to offer psychological support (Vocal Local) and Entonox if required.

The clinician visualised the cervix, cleaned it with antiseptic solution (Unisept ${ }^{\mathbb{R}}$ ) and applied a single tooth volsellum to stabilise the anterior lip of cervix. The LA consisted of a direct intracervical block using $6.6 \mathrm{ml} 3 \%$ mepivacaine hydrochloride (Scandonest, Septodont ltd.) infiltration deep at the cervical isthmus level at 12, 3, 5, 6, 7, and 9 o'clock positions using dental needle (Solo Supra). The cervix was dilated to a minimum of $7 \mathrm{~mm}$ and the MVA curette of 6 to $9 \mathrm{~mm}$ was introduced into the uterine cavity to commence the aspiration using a 60-ml self-locking syringe (Ipas MVA Plus ${ }^{\circledR}$ aspirator). Typically, the MVA procedure consisted of no more than three separate suction events, initially rotating the syringe and then finishing with an in and out motion, lasting in total between $60 \mathrm{~s}$ to $2 \mathrm{~min}$. The products retrieved were sent to pathology for histopathology evaluation.

Immediately, post-procedure, $50-100 \mathrm{mg}$ diclofenac and $1 \mathrm{~g}$ paracetamol were given rectally for pain relief. When patients could not be prescribed diclofenac due to contraindications then co-dydramol two tablets or Tramadol $100 \mathrm{mg}$ was given orally. In all emergency cases, IV morphine was given in a titrated 5-mg bolus dose up to a maximum of 20mg dose with Entonox ${ }^{\circledR}$.

Anti-D prophylaxis was administered to all Rhesus negative women. Oxygen saturation monitoring was carried out for at least $2 \mathrm{~h}$ prior to discharge in women who underwent emergency MVA and had IV morphine. Patients were usually discharged within $2 \mathrm{~h}$ of the procedure. All women were advised to rest for the remainder of the day and were advised to return to work usually within $24-48 \mathrm{~h}$.

On discharge, the patient was given the ward's contact number, in case of problems, and analgesia in the form of diclofenac or co-dydramol. The patient was instructed to do a urine pregnancy test 2 weeks after the procedure. No followup was specifically arranged. The patient was instructed to get in contact if experiencing heavy bleeding, pyrexia, severe abdominal pain, abnormal vaginal discharge or had a positive pregnancy test.

A computer database was used to record relevant information relating to the procedure. Data was collected immediately post-procedure and updated once the patient was discharged. Recorded data included any post procedural complications and analgesia requirements by the operating clinician. Patient experience was evaluated in a sample of patients using an anonymous questionnaire survey on the gynaecology ward by the staff nurses over a 2-month period $(n=28)$. This included questions on acceptability, anxiety and pain before and after the procedure and free comments. The collected data was then analysed using SPSS (version 16, IBM SPSS Statistics).

\section{Findings}

A total of 131 women with USS confirmed early miscarriage at less than 12 weeks of completed gestation or incomplete miscarriage underwent the MVA procedure. The majority of procedures were carried out in a dedicated outpatient setting in EPAU (82\%) whilst a minority in the gynaecology ward 
$(13.0 \%)$, theatre $(4.6 \%)$ whilst piloting the service, and A\&E $(0.8 \%)$ for emergency procedures.

The mean gestation age was 8.3 weeks $( \pm 1.8$ weeks) (Table 1). The seven patients that had MVA at gestation greater than 12 weeks were patients with an incomplete miscarriage.

The majority of patients $(87.0 \%)$ required an LA cervical block for the procedure. Most patients were managed immediately post operatively with diclofenac and/or paracetamol combination $(81.7 \%)$. Only four patients required the use of anti-emetics immediately post-procedure.

Vaginal misoprostol for cervical priming was administered in all elective missed miscarriage patients. Of the 127 patients with results recorded, $71(54.2 \%)$ had an open

Table 1 Results of women managed with MVA-LA in an outpatient setting for early miscarriage, $n=131$ ( $n$ percentage)

\begin{tabular}{|c|c|}
\hline \multicolumn{2}{|l|}{ Indication for MVA } \\
\hline Missed miscarriage & $112(85 \%)$ \\
\hline Incomplete miscarriage & $19(15 \%)$ \\
\hline \multicolumn{2}{|l|}{ Mean gestation age by USS (weeks) } \\
\hline$<9$ & $91(70 \%)$ \\
\hline $9-12$ & $33(25 \%)$ \\
\hline$>12$ & $7(5 \%)$ \\
\hline \multicolumn{2}{|c|}{ Intra-operative analgesia (some patients required multiple analgesics) } \\
\hline Cervical block LA & $114(87 \%)$ \\
\hline None & $21(16 \%)$ \\
\hline Morphine & $12(9 \%)$ \\
\hline Entonox $\mathbb{R}$ & $6(5 \%)$ \\
\hline \multicolumn{2}{|l|}{ Cervical dilatation required } \\
\hline Yes & $72(55 \%)$ \\
\hline No & $55(42 \%)$ \\
\hline Not recorded & $4(3 \%)$ \\
\hline \multicolumn{2}{|l|}{ Intra-operative complications } \\
\hline None & $126(96 \%)$ \\
\hline Uterine perforation (suspected) & $1(1 \%)$ \\
\hline Severe haemorrhage & $0(0 \%)$ \\
\hline Cervical injury & $2(2 \%)$ \\
\hline Vasovagal & $2(2 \%)$ \\
\hline \multicolumn{2}{|c|}{ Post-operative analgesia (some patients required multiple drugs) } \\
\hline Diclofenac and paracetamol & $107(82 \%)$ \\
\hline Codeine & $4(3 \%)$ \\
\hline Morphine/pethidine & $8(6 \%)$ \\
\hline Entonox ${ }^{\circledR}$ & $18(14 \%)$ \\
\hline None & $10(8 \%)$ \\
\hline \multicolumn{2}{|l|}{ Post-operative complications } \\
\hline None reported & $129(98 \%)$ \\
\hline RPOC & $1(1 \%)$ \\
\hline USS to confirm complete evacuation & $1(1 \%)$ \\
\hline
\end{tabular}

MVA-LA manual vacuum aspiration under local anaesthesia, USS ultrasound scan, $R P O C$ retained products of conception cervical os at the time of procedure and only $16(22.5 \%)$ required further cervical dilation.

All women had a successful evacuation of the uterus. Only five $(3.8 \%)$ cases had intra-operative complications; two with vasovagal symptoms, two with cervical injury and one with suspected uterine perforation which was managed with a short course of antibiotics and no further intervention was required. There were no major, life threatening or fatal complications. All patients reported minimal or mild vaginal bleeding after the procedure. None of the patients required a blood transfusion. All patients were managed as a day case.

Data about procedure acceptability and experience are shown in Table 2 . The majority ( $82 \%$ ) reported that procedure duration was shorter or as expected; $68 \%$ said they would recommend this option to a friend, and $61 \%$ stated that they would choose this method again. Level of pain during the procedure was satisfactory with only $11 \%$ reported unbearable pain which settled after the procedure.

Table 2 Post procedure responses to questionnaire about acceptability and experience with MVA under LA, $n=28$ (data showed in percentage (number of patients))

\begin{tabular}{|c|c|c|c|}
\hline \multicolumn{4}{|c|}{ Overall experience (as compared to what was expected) } \\
\hline Much better & \multicolumn{3}{|l|}{$61 \%$} \\
\hline A bit better & \multicolumn{3}{|l|}{$14 \%$} \\
\hline As expected & \multicolumn{3}{|l|}{$18 \%$} \\
\hline Worse & \multicolumn{3}{|l|}{$0 \%$} \\
\hline No reply & \multicolumn{3}{|l|}{$7 \%$} \\
\hline \multicolumn{4}{|c|}{ Procedure duration? } \\
\hline As expected & \multicolumn{3}{|l|}{$82 \%$} \\
\hline Longer & \multicolumn{3}{|l|}{$14 \%$} \\
\hline No answer & \multicolumn{3}{|l|}{$4 \%$} \\
\hline \multicolumn{4}{|c|}{ Happy to recommend? } \\
\hline Yes & \multicolumn{3}{|l|}{$68 \%$} \\
\hline No & \multicolumn{3}{|l|}{$21 \%$} \\
\hline Don't know & \multicolumn{3}{|l|}{$11 \%$} \\
\hline \multicolumn{4}{|c|}{ Choose the method again? } \\
\hline Yes & \multicolumn{3}{|l|}{$61 \%$} \\
\hline No & \multicolumn{3}{|l|}{$11 \%$} \\
\hline \multirow[t]{2}{*}{ Don't know } & \multicolumn{3}{|l|}{$29 \%$} \\
\hline & During procedure & At $1 \mathrm{~h}$ & At discharge \\
\hline \multicolumn{4}{|c|}{ Patients with anxiety (\%) } \\
\hline None & $14 \%$ & $46 \%$ & $54 \%$ \\
\hline Moderate & $61 \%$ & $50 \%$ & $39 \%$ \\
\hline Severe & $25 \%$ & $4 \%$ & $0 \%$ \\
\hline No reply & $0 \%$ & $0 \%$ & $7 \%$ \\
\hline \multicolumn{4}{|c|}{ Patients with pain $(\%)$} \\
\hline None & $18 \%$ & $18 \%$ & $39 \%$ \\
\hline Moderate & $68 \%$ & $79 \%$ & $54 \%$ \\
\hline Severe & $11 \%$ & $4 \%$ & $0 \%$ \\
\hline No reply & $3 \%$ & $0 \%$ & $7 \%$ \\
\hline
\end{tabular}




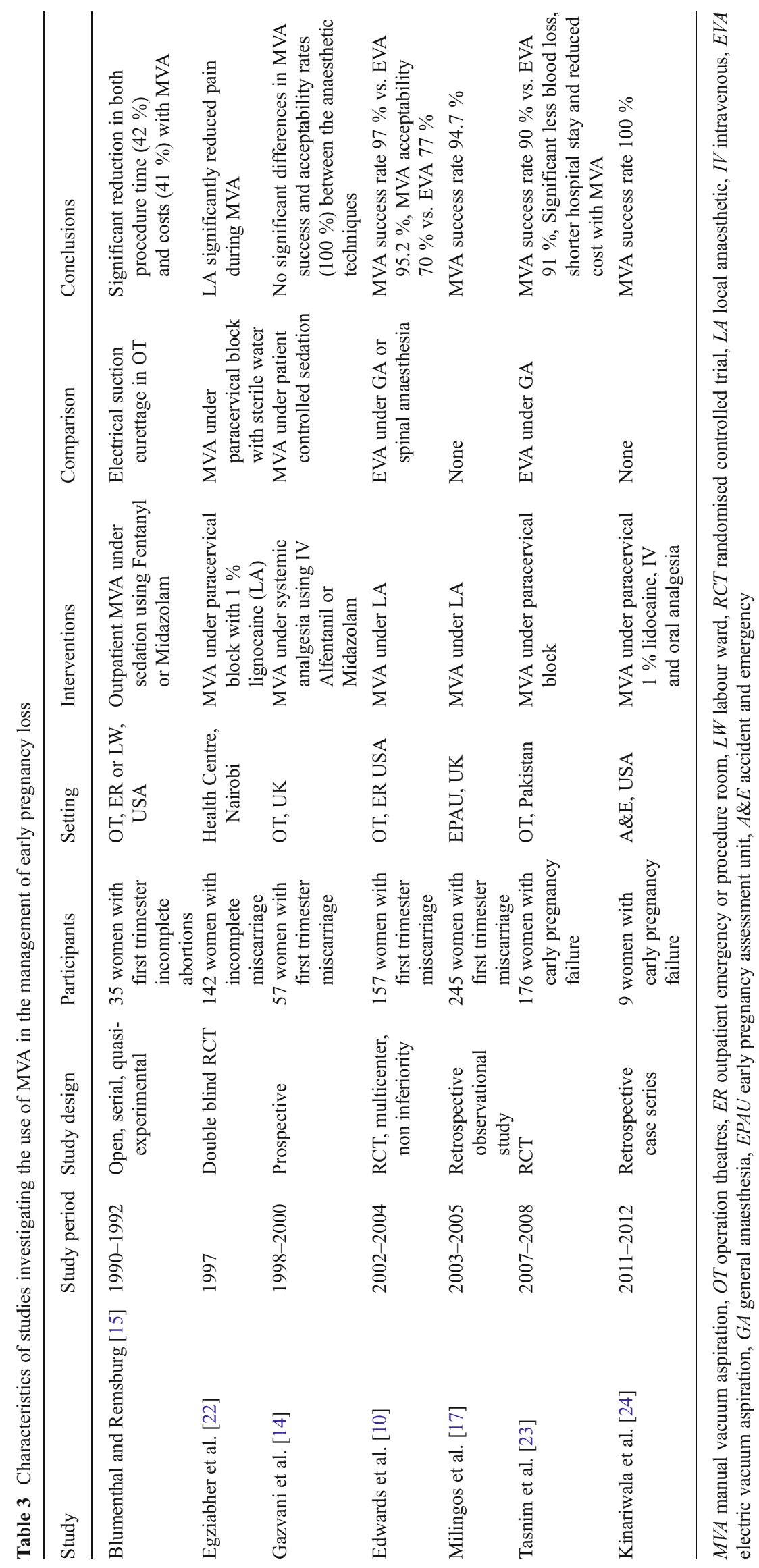




\section{Discussion}

The data from our study suggest that MVA under LA can be successfully used for the management of confirmed early missed or incomplete miscarriages in an outpatient setting.

The procedure was introduced in our hospital with the aim of providing a safe, effective and value-for-money alternative to other methods of surgical management, which increased convenience and reduced recovery time. Milingos et al. [17], in a retrospective observational study, showed that the procedure was effective in $95 \%$ cases with no major complications and our experiences from the first 2 years of its use support these findings. The procedure was completed successfully in all cases and there were no major complications in our cohort.

Cervical priming with vaginal misoprostol before MVA has shown to significantly reduce the need for cervical dilation and improve the efficacy of the procedure [19]. For many of the elective patients in the study, the use of misoprostol alone before procedure was enough to ensure that the cervix was dilated, allowing safer evacuation by minimising cervical trauma related to instrumental dilation and reducing the discomfort of cervical dilation.

MVA is a procedure in which most of the patients experience a moderate level of pain [20]; however, local anaesthesia in the form of a cervical block provides effective pain control ensuring MVA is a quick, inexpensive and the preferred alternative to other surgical methods requiring GA [20]. For many patients in our study, vaginal misoprostol and LA to the cervix (if required) was adequate to complete the procedure. It is important, however, to ensure that the level of pain relief can be increased if required during the evacuation and this can be achieved with the use of Entonox ${ }^{\circledR}$ and/or IV morphine.

Although further research is needed to examine acceptability of MVA among users, findings of our survey indicate that women's perceptions and experiences with MVA are favourable. Women often feel nervous about undergoing uterine evacuation under LA, and their anxiety aggravates their perception of pain. Conversely, women who feel less anxious are less likely to perceive pain. Therefore the role of a nurse or HCA to psychologically support the patient cannot be undermined as it is important that the patient's attention is diverted during the procedure (Vocal Local). We are currently studying patients' acceptability of MVA in a trial involving patient questionnaire and interviews of their experience.

Although women were not followed up after their discharge, all women were given the ward's contact number in case of any problems and were advised to contact on a 24-h basis. However, there is a possibility that a few patients may have seen their local GPs with minor problems and these would have been missed in the data analysis.

The World Health Organization (WHO) has listed MVA as an effective and safe method of surgical management of miscarriage [21], however it remains underused in the UK [14, 16, 17] (Table 3).

The unfamiliarity of this method and lack of confidence among clinicians when counselling women about options of surgical evacuation may be the contributing factor of its infrequent use in the UK. Given the current economic climate and the benefits shown by our study, it is an option that requires further consideration as a more efficient alternative method of surgical evacuation. MVA-LA for evacuation of early miscarriage is an ideal procedure to be taken into the ambulatory outpatient setting. Although the procedure was mostly performed by two hospital consultants in our study, this simple and mostly complication-free procedure can be easily performed by trainees under direct or indirect supervision as the learning curve for this is a simple procedure.

Our data suggest that MVA-LA can be a feasible and effective therapeutic alternative to conventional suction curettage options in the management of first trimester pregnancy losses. It may result in considerable improvements in patient care and patient choices who do not wish for a general anaesthesia or prolonged conservative/medical treatment, and substantial savings for health service. However, these findings now need to be assessed in the context of randomised trials comparing MVA-LA with other conventional suction curettage methods for managing early pregnancy loss.

\section{Conclusions}

The outcome data of MVA under LA for early pregnancy loss are consistent with previously published studies. The results are favourable and MVA-LA for early pregnancy loss could be a safe, efficient and acceptable alternative to surgical management methods under GA. However, a welldesigned randomised controlled trial is required to confirm these findings. This easily performed procedure can be undertaken in a variety of outpatient settings. Moreover, it is efficient, safe, provides better patient experience and increases patient's choice, making it suitable to respond to current healthcare needs.

Conflict of interest On behalf of all authors, the corresponding author states that there is no conflict of interest.

\section{References}

1. Office of National Statistics (2011) Conception in England and Wales 2009. Office of National Statistics [Online]. Available at http://www. ons.gov.uk/ons/rel/vsob1/conception-statistics-england-and-wales/ 2009/index.html. Accessed 11 March 2013 
2. Hospital Episode Statitistics (2010) Total deliveries, miscarriages and ectopic pregnancies per 100 deliveries, 1997-98 to 2009-10. Hospital Episode Statistics [Online]. Available at http://www.hesonline.nhs.uk/ Ease/servlet/ContentServer?siteID=1937\&categoryID=1064. Accessed 11 March 2013

3. Trinder J, Brocklehurst P, Porter R et al (2006) Management of miscarriage: expectant, medical, or surgical? Results of randomised controlled trial (miscarriage treatment (MIST) trial). BMJ 332(7552):1235-1240

4. Ankum WM, Wieringa-De Waard M, Bindels PJ (2001) Management of spontaneous miscarriage in the first trimester: an example of putting informed shared decision making into practice. BMJ 322(7298):1343-1346

5. Shelley JM, Healy D, Grover S (2005) A randomised trial of surgical, medical and expectant management of first trimester spontaneous miscarriage. Aust N Z J Obstet Gynaecol 45(2): $122-127$

6. Petrou S, McIntosh E (2009) Women's preferences for attributes of first-trimester miscarriage management: a stated preference discretechoice experiment. Value Health 12(4):551-559

7. Ryan M, Hughes J (1997) Using conjoint analysis to assess women's preferences for miscarriage management. Health Econ 6:261-273

8. Kulier R, Fekih A, Hofmeyr GJ et al (2001) Surgical methods for first trimester termination of pregnancy. Cochrane Database Syst Rev 4(CD002900)

9. Bradley E, Hamilton-Fairley D (1998) Managing miscarriage in early pregnancy assessment units. Hosp Med 59:451-456

10. Edwards S, Tureck R, Fredrick M et al (2007) Patient acceptability of manual versus electric vacuum aspiration for early pregnancy loss. J Womens Health (Larchmt) 16(10):1429-1436

11. Wen J, Cai QY, Deng F, Li YP (2008) Manual versus electric vacuum aspiration for first-trimester abortion: a systematic review. BJOG 115(1):5-13

12. Bird ST, Harvey SM, Beckman LJ et al (2003) Similarities in women's perceptions and acceptability of manual vacuum aspiration and electric vacuum aspiration for first trimester abortion. Contraception 67(3):207-212
13. Westfall JM, Sophocles A, Burggraf H et al (1998) Manual vacuum aspiration for first-trimester abortion. Arch Fam Med 7(6):559-562

14. Gazvani R, Honey E, MacLennan FM et al (2004) Manual vacuum aspiration (MVA) in the management of first trimester pregnancy loss. European Journal of Obstetrics \& Gynecology and Reproductive Biology 112(2):197-200

15. Blumenthal PD, Remsburg RE (1994) A time and cost analysis of the management of incomplete abortion with manual vacuum aspiration. Int J Gynaecol Obstet 45(3):261-267

16. Dean G, Cardenas L, Darney P et al (2003) Acceptability of manual versus electric aspiration for first trimester abortion: a randomized trial. Contraception 67(3):201-206

17. Milingos DS, Mathur M, Smith NT et al (2009) Manual vacuum aspiration: a safe alternative for the surgical management of early pregnancy loss. BJOG 116(9):1268-1271

18. Clark TJ, Gupta JK (2005) Handbook of outpatient hysteroscopy: a complete guide to diagnosis and therapy. Hodder Arnold, London

19. Mittal S, Sehgal R, Aggarwal S et al (2011) Cervical priming with misoprostol before manual vacuum aspiration versus electric vacuum aspiration for first-trimester surgical abortion. Int J Gynaecol Obstet 112(1):34-39

20. López JC, Vigil-De Gracia P, Vega-Malek JC et al (2007) A randomized comparison of different methods of analgesia in abortion using manual vacuum aspiration. Int J Gynaecol Obstet 99(2):91-94

21. World Health Organization (1991) Essential elements of obstetric care at first referral level. Geneva: WHO. Available at http://whqlibdoc. who.int/publications/1991/9241544244.pdf. Accessed 11 March 2013

22. Egziabher TG, Ruminjo JK, Sekadde-Kigondu C (2002) Pain relief using paracervical block in patients undergoing manual vacuum aspiration of uterus. East Afr Med J 79(10):530-534

23. Tasnim N, Mahmud G, Fatima S et al (2011) Manual vacuum aspiration: a safe and cost-effective substitute of electric vacuum aspiration for the surgical management of early pregnancy loss. J Pak Med Assoc 61(2):149-153

24. Kinariwala M, Quinley KE, Datner EM et al (2013) Manual vacuum aspiration in the emergency department for management of early pregnancy failure. Am J Emerg Med 31(1):244-247 